\title{
The synthesis, modification, and application of nanosilica in polymethyl methacrylate denture base
}

\author{
Pornpot JIANGKONGKHO ${ }^{1}$, Mansuang ARKSORNNUKIT ${ }^{1}$ and Hidekazu TAKAHASHI ${ }^{2}$ \\ ${ }^{1}$ Department of Prosthodontics, Faculty of Dentistry, Chulalongkorn University, 34 Henri-Dunant Road, Patumwan, Bangkok 10330, Thailand \\ ${ }^{2}$ Oral Biomaterials Engineering, Graduate School of Medical and Dental Sciences, Tokyo Medical and Dental University, 1-5-45 Yushima, Bunkyo-ku, \\ Tokyo 113-8549, Japan \\ Corresponding author, Mansuang ARKSORNNUKIT; E-mail: mansuang@yahoo.com
}

\begin{abstract}
This study aimed to investigate amount of $\gamma$-methacryloxypropyltrimethoxysilane (MPS) silanized on experimental nanosilica particles (NPs), amount of NP and amount of MPS silanized NP on flexural strength (FS), flexural modulus (FM), and fracture toughness (FT) of NP reinforced polymethyl methacrylate (PMMA). The chemisorbed amount of MPS was determined using elemental analysis. Six groups $(n=8)$ were prepared with chemisorbed amount and mixed with PMMA-monomer to make $0.25,0.5,1,5,10$ and $15 \%(w / w)$ of NP reinforced PMMA. PMMA without NP served as control. Seven groups $(n=8)$ were prepared with $1 \%$ of NP silanized with $0,0.061,0.123,0.246,0.493,0.987$, and $1.974 \mathrm{~g}_{\mathrm{MPS}} / \mathrm{g}_{\text {silica }}$ and mixed with PMMA-monomer to make NP reinforced PMMA. FS, FM, and FT were determined using 3-point bending test. One-way ANOVA and multiple comparisons showed that $0.246 \mathrm{~g}_{\mathrm{MPS}} / \mathrm{g}_{\text {silica }}$ of $1 \%$ amount of silanized NP group was significantly highest in FS, FM, and FT compared to the others $(p<0.05)$.
\end{abstract}

Keywords: Flexural properties, Modification, Nanosilica, Silane coupling agent, Synthesis

\section{INTRODUCTION}

Nanotechnology is based on the use of matter at dimensions between 1-100 nanometers (nm). Nanoparticles have a very high surface area to volume ratio, resulting in increased molecular interaction between the polymer and nanoparticles in a composite nanomaterial ${ }^{1)}$. At the nanoscale, the inorganic nanoparticles are used to reinforce the polymer matrix. However, the effect of nanoparticle enhancement depends on particle size and degree of dispersion ${ }^{2}$.

Nanosilica particles (NPs) are frequently used as fillers to improve a material's properties, such as abrasion resistance, mechanical properties, and refractive index. The small size and homogeneous distribution of the nanoparticles in the matrix are essential for optical transparency and optimal mechanical properties ${ }^{3)}$. The Stöber method was developed to produce uniformsize NPs using ammonia catalyzed hydrolysis and condensation using low molecular-weight alcohol as a solvent ${ }^{4)}$. The size and dispersion of these particles are controlled by the concentration of tetraethyorthosilicate, water, and ammonia ${ }^{5-8}$. However, inorganic particles cannot be dispersed in a nonpolar organic polymer unless a dispersing agent is used. Silane coupling agents are often used as a dispersing agent to form stable chemical bonds between the inorganic particles and organic polymer material. Moreover, silanization improved the dispersive stability of the particles in a polymer and enhanced the mechanical properties of polymer based composite materials ${ }^{9}$. The high viscosity of organic polymers makes it difficult to disperse nanoparticles

Color figures can be viewed in the online issue, which is available at J-STAGE.

Received May 1, 2017: Accepted Oct 23, 2017

doi:10.4012/dmj.2017-142 JOI JST.JSTAGE/dmj/2017-142 in the polymer matrix. Low dispersion limits the effect of the nanoparticles on improving polymer mechanical properties. Thus, predispersing the nanoparticles in the monomer or pre-polymer before preparation of the nanocomposites is recommended ${ }^{2}$.

$\gamma$-methacryloxypropyltrimethoxysilane (MPS) is the silane coupling agent most commonly used in dentistry to modify the silica surface ${ }^{9)}$. An important factor is the amount of MPS needed to form a monolayer on the NP surface. Theoretical calculations generated two estimated MPS amounts, depending on the MPS molecule orientation ${ }^{10}$. If the MPS molecule is oriented perpendicular to the surface, it is estimated that 6.9 $\mu \mathrm{mol}$ of MPS is needed to create a monolayer covering $1.0 \mathrm{~m}^{2}$ of the particle surface. If the MPS molecule is oriented parallel to the surface, resulting in hydrogen bonding between the MPS carbonyl group and Si-OH on NP surface also siloxane bond between $\mathrm{Si}-\mathrm{OH}$ of MPS and Si-OH on NP surface, only $3.0 \mu \mathrm{mol}$ of MPS is needed for a monolayer covering $1.0 \mathrm{~m}^{2}$ of the particle surface ${ }^{10)}$. These calculations were based on a computer simulation. However, the calculated amount of MPS required monolayer coverage on the particle surface by Arkles's equation ${ }^{11)}$ was $12.82 \mu \mathrm{mol} / \mathrm{m}^{2}$. Posthumus et al. ${ }^{12)}$ reported that the actual values can deviate from both Arkles's equation and Posthumus et al.'s calculation due to incomplete coverage and increased MPS molecular weight due to homocondensation. The homocondensed molecule is too large to react with the silica surface, resulting in multilayer formation. Söderholm and Shang ${ }^{13)}$ found that the amount of MPS needed to form a monolayer on the silica surface was $1.59 \mu \mathrm{mol} / \mathrm{m}^{2}$. This amount was approximately 8 times lower than that based on Arkles's equation $\left(12.82 \mu \mathrm{mol} / \mathrm{m}^{2}\right)$. However, the actual amounts 
of MPS used in silanization were lower than the amount needed for complete monolayer coverage ${ }^{12,13)}$, based on both computer simulation and Arkles's equation. The optimal amount MPS required for NP silanization is still unknown.

Polymethyl methacrylate (PMMA) has been commonly used since the 1940's to fabricate denture base $^{14)}$. The advantages of PMMA are low cost, simple fabrication process, light weight, satisfactory esthetics, color matching ability, and easy to finish and polish ${ }^{15}$. However, some disadvantages exist, including low strength and toughness. Many studies have been performed to improve the mechanical properties of denture base materials by adding fillers to the PMMA denture base ${ }^{16,17)}$. It was reported that alumina with a chemisorbed MPS monolayer adequately improved the mechanical properties of PMMA denture base ${ }^{17)}$. However, there are no studies concerning the effect of the amount of MPS on NPs on the mechanical properties of NP reinforced PMMA. In this study, NPs with a chemisorbed silane monolayer were predispersed in PMMA liquid monomer to obtain a homogenous suspension, which was subsequently mixed with PMMA polymer powder. It was hypothesized that this process would generate a homogenous material that improved the mechanical properties of PMMA denture base.

Therefore, the objectives of this study were to investigate the chemisorbed amounts of silanized on NPs and to investigate the effect of various amount of NPs and various amount of MPS silanized on the NPs on mechanical properties of NPs reinforced PMMA denture base. The null hypotheses were that there would be no differences in the mechanical properties of PMMA denture base reinforced with various amount of NPs and amount of MPS silanized on the NPs.

\section{MATERIALS AND METHODS}

Precursor, silane coupling agent, and solutions

The precursor, silane coupling agent, and solutions used in this study, and their manufacturer, are shown in Table 1 . The chemicals were used as received.

\section{NPs synthesis and modification}

Spherical NPs were prepared by hydrolysing tetraethoxysilane (TEOS) in ethanol (ETH), distilled water $\left(\mathrm{H}_{2} \mathrm{O}\right)$, and ammonium hydroxide $\left(\mathrm{NH}_{4} \mathrm{OH}\right)$. The particle size was controlled by the concentrations of TEOS, $\mathrm{H}_{2} \mathrm{O}$, and $\mathrm{NH}_{4} \mathrm{OH}$ in ETH, as previously described $^{5)}$. In this study, $36 \mathrm{~nm}$-size NPs were synthesized from the concentrations of TEOS, $\mathrm{H}_{2} \mathrm{O}$ and $\mathrm{NH}_{4} \mathrm{OH}$ equal to $0.322,1$ and $0.233 \mathrm{~mol} / \mathrm{L}$, respectively. Eight milliliters of TEOS was added to $100 \mathrm{~mL}$ of absolute ETH and magnetically stirred at room temperature (RT) $\left(23 \pm 2^{\circ} \mathrm{C}\right)$ for $10 \mathrm{~min}$. Next, $2 \mathrm{~mL}$ of $\mathrm{H}_{2} \mathrm{O}$ was added drop by dropping into the reaction media to facilitate TEOS hydrolysis. After $90 \mathrm{~min}, 1 \mathrm{~mL}$ of $\mathrm{NH}_{4} \mathrm{OH}$ (catalyst) was added to the reaction mixture. The reaction continued for 7 days to obtain monodispersed NPs.

The amount of MPS used for NP silanization was calculated using the modified Posthumus's equation ${ }^{12)}$ as follows:

$X=m_{\text {silica }} \times M W_{\mathrm{MPS}} \times M_{\mathrm{MPS}} \times B E T_{\text {silica }} \times 10^{-6}$

where, $X$ is the amount of silane $(\mathrm{g}), m_{\text {silica }}$ is the amount of silica $(\mathrm{g}), M W_{M P S}$ is the molecular weight of MPS $(248.35 \mathrm{~g} / \mathrm{mol}), M_{M P S}$ is the amount of required chemisorbed MPS $\left(6.9 \mu \mathrm{mol} / \mathrm{m}^{2}\right)$, and $B E T_{\text {silica }}$ is the NP surface area $\left(576 \mathrm{~m}^{2} / \mathrm{g}\right)$.

The NPs were silanized with $0,0.061,0.123$, $0.246,0.493,0.987$, and $1.974 \mathrm{~g} \mathrm{gPS}_{\mathrm{MP}} / \mathrm{g}_{\text {silica }} \mathrm{MPS}$. The MPS was pre-hydrolyzed in $80 \% \mathrm{ETH}$ at RT for $1 \mathrm{~h}$. The hydrolyzed MPS was added to the NP suspension

Table 1 Precursor, silane coupling agent and solutions used in the present study

\begin{tabular}{|c|c|c|c|c|c|}
\hline Name & Concentration (\%) & Code & Brand & Mfg. & Lot No. \\
\hline \multicolumn{6}{|l|}{ Precursor } \\
\hline Tetraethoxysilane & 98 & TEOS & SIGMA-ALDRICH ${ }^{\circledR}$ & $\begin{array}{l}\text { SIGMA-ALDRICH }{ }^{\circledR} \text {, } \\
\text { St. Louis, MO, USA }\end{array}$ & WXBC1471V \\
\hline \multicolumn{6}{|l|}{ Silane coupling agent } \\
\hline $\begin{array}{l}\gamma \text {-methacryloxy } \\
\text { propyltrimethoxysilane }\end{array}$ & 99 & MPS & SIGMA-ALDRICH $^{\circledR}$ & SIGMA-ALDRICH ${ }^{\circledR}$ & SHBD3265V \\
\hline \multicolumn{6}{|l|}{ Solutions } \\
\hline Ethanol & 99.90 & ETH & EMSURE $^{\circledR}$ & $\begin{array}{l}\text { Merck, Darmstadt, } \\
\text { Germany }\end{array}$ & K47648083610 \\
\hline Ammonium hydroxide & $28-30$ & $\mathrm{NH}_{4} \mathrm{OH}$ & J.T.Baker & $\begin{array}{l}\text { Avantor Performance } \\
\text { Materials, Center } \\
\text { Valley, PA, USA }\end{array}$ & 101273 \\
\hline Isopropanol & 99.50 & ISP & UNIVAR & $\begin{array}{l}\text { Ajax Finechem, } \\
\text { NSW, Australia }\end{array}$ & 1506196057 \\
\hline
\end{tabular}


and stirred using a magnetic stirrer at $200 \mathrm{rpm}$ for $2 \mathrm{~h}$ at $\mathrm{RT}$, and then refluxed at $70^{\circ} \mathrm{C}$ for $4 \mathrm{~h}$. At the end of the reaction, the mixture was allowed to cool and divided into two parts for analysis. The first part was dried by evaporating the solvent in an oven (Memmert, Schwabach, Germany) at $50 \pm 5^{\circ} \mathrm{C}$. This process resulted in a mixture of silanized NP, unreacted MPS, and homocondensated MPS, which is referred to as the dried sample. The other part was diluted with isopropanol at a $3: 1(\mathrm{v} / \mathrm{v})$ ratio to improve the solubility of the homocondensated MPS. This sample was centrifuged using high speed centrifugation (Avanti ${ }^{\circledR} \mathrm{J}$-E, Bechman Coulter, Indianapolis, IN, USA) at 20,000 rpm for $2 \mathrm{~h}$ at $\mathrm{RT}^{12)}$. The clear supernatant, which contained the homocondensated MPS and unreacted MPS, was decanted from the sediment. This sediment was composed of NPs silanized with MPS. This sediment is referred to as the centrifuged sample. The dried and centrifuged samples were dried at $50 \pm 5^{\circ} \mathrm{C}$ in an oven for at least $16 \mathrm{~h}$.

\section{NPs characterization}

1. Transmission electron microscopy (TEM)

The morphology and distribution of the experimental NPs in solution were observed using a TEM (JEM2100, JEOL, Tokyo, Japan) at an acceleration voltage of $80 \mathrm{kV}$. One drop of the NP suspension was evaporated on a carbon-coated copper grid. The morphology and distribution of NPs are shown in Fig. 1.

The morphology and distribution of the NPs in the NP reinforced PMMA denture base were evaluated using a TEM operated at an acceleration voltage of 120 $\mathrm{kV}$. Thin sections, approximately $200 \mathrm{~nm}$ thick, were prepared using an ultramicrotome (Leica EM UC7, Leica Microsystems, Vienna, Austria) equipped with a diamond knife at RT without chemical etching.

\section{Dynamic light-scattering evaluation (DLS)}

The size and distribution of the NPs were determined using a Zetasizer with dynamic light-scattering and Stokes-Einstein autocorrelation function (Zetasizer, Malvern Instrument, Malvern, UK).

\section{Automatic physisorption analysis}

The surface area of the NPs were measured by using an automatic physisorption analyzer (Micromeritics ASAP 2000, Micromeritics Instrument, Norcross, GA, USA) with adsorption-desorption of nitrogen isotherm at $77 \mathrm{~K}$.

4. Fourier transform infrared spectrophotometry (FTIR) The silanized MPS was characterized using FTIR measurements with a narrow bandpass mercurycadmium-telluride (MCT) detector. The dried and centrifuged specimens of silanized NP as described above were analyzed using FTIR spectrophotometer (PerkinElmer 2000, PerkinElmer, Waltham, MA, USA). Each IR spectra was collected from $400-4,000 \mathrm{~cm}^{-1}$ under the nitrogen purge. Prior to the measurement, $100 \mathrm{mg}$ of the dried or centrifuged sample were mixed with $1 \mathrm{~g}$ of $\mathrm{KBr}$ powder and IR spectra were taken on a

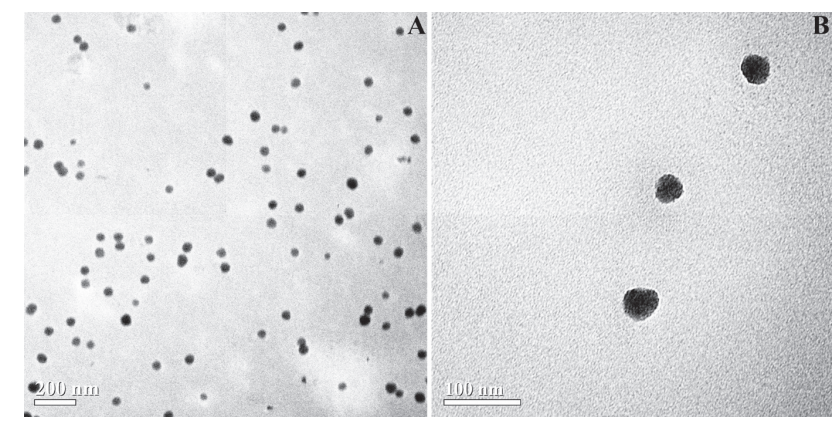

Fig. 1 TEM images of NP size and distribution. A: $20 \mathrm{k}$ magnification, B: 40k magnification.

PerkineElmer 2000 spectrometer.

\section{Organic element analysis}

The carbon content on the silanized NP surface was analyzed to determine the amount of chemisorbed MPS on the NP surface using an organic element analyzer (Thermo FLASH 2000, Thermo Fisher Scientific, Waltham, MA, USA). The amount of carbon on the NP surface was calculated to determine the MPS content. The MPS content was determined using the number of carbon atoms in each MPS molecule; one molecule of MPS contains 7 carbon atoms. Surface coverage $(C)$ was calculated, as follows ${ }^{18)}$ :

$$
C=M_{\mathrm{MPS}} \times N_{\mathrm{A}} \times 10^{-18}
$$

where, $C$ is surface coverage (molecule/ $/ \mathrm{nm}^{2}$ ), $M_{\mathrm{MPs}}$ is the amount of MPS on the NP surface $\left(\mu \mathrm{mol} / \mathrm{m}^{2}=\mu \mathrm{mol} \times 10^{-18} /\right.$ $\left.\mathrm{nm}^{2}\right)$, and $N_{\mathrm{A}}$ is Avogadro's number $\left(6.02 \times 10^{23}\right.$ molecules/ mol).

Flexural strength (FS) and flexural modulus (FM) evaluation of NPs reinforced PMMA denture base

1. Effect of the amount of NPs

The elemental analysis and FTIR results indicated that $0.246 \mathrm{~g}_{\mathrm{MPS}} / \mathrm{g}_{\text {silica }}$ MPS created a chemisorbed monolayer on the NPs. Therefore, $0.246 \mathrm{~g}_{\mathrm{MPS}} / \mathrm{g}_{\text {silica }}$ silanized NPs were used. The silanized NPs were divided into 7 groups $(n=8): 0$ (control), $0.25,0.5,1,5,10$, and $15 \%(\mathrm{w} / \mathrm{w})$ silanized NPs. Heat-polymerized PMMA (Triplex hot, Ivoclar Vivadent, Schaan, Liechtenstein) was used in this study. Each silanized NP group was mixed with the PMMA monomer using a rotor stator mixer at 3,000 rpm for $10 \mathrm{~min}$ to form a homogeneous suspension. This is referred to as the modified monomer. The PMMA powder and modified monomer of each group was mixed at a ratio of $23.4 \mathrm{~g}$ powder to $10 \mathrm{~mL}$ modified monomer. After the dough stage, the mixture was placed in a flask, pressed, and heat-polymerized with heat up to $100^{\circ} \mathrm{C}$ and boiled for $45 \mathrm{~min}$. After the flask cooled to RT, the specimens were deflasked.

\section{Effect of the amount of MPS}

Based on the FS and FM results of the $0.246 \mathrm{~g}_{\mathrm{MPS}} / \mathrm{g}_{\text {silica }}$ of $0-15 \%$ silanized NPs groups, $1 \%$ of silanized NPs was selected when determining the effect of the amount of 
MPS. The specimens were divided into 7 groups $(n=8)$ : $0,0.061,0.123,0.246,0.493,0.987$, and $1.974 \mathrm{~g}_{\mathrm{MPS}} / \mathrm{g}_{\text {silica }}$ MPS. The FS and FM values of the control and 0.246 $\mathrm{g}_{\text {MPS }} / \mathrm{g}_{\text {silica }}$ of $1 \%$ of silanized NPs groups from the section above were used in analyzing the effect of the amount of MPS results. The specimens in these groups were fabricated as described above and evaluated for FS and FM.

\section{FS and FM test}

FS and FM were determined using a three-point bending test according to ISO 20795-1:2013 ${ }^{19}$. Bar-shaped specimens, $10 \mathrm{~mm}$-wide, $64 \mathrm{~mm}$-long, and $3.3 \mathrm{~mm}$-thick, were fabricated as described above and polished with \#500, \#1000, and \#1200 wet silicon carbide paper using a polishing machine (Nano2000, PACE Technologies, Tucson, AZ, USA) to achieve the required dimensions of $10.0 \pm 0.2 \times 64.0 \times 3.2 \pm 0.2 \mathrm{~mm}$. The width and thickness of each specimen were measured with a digital micrometer (Mitutoyo IP65, Mitutoyo, Kanagawa, Japan). To minimize edge failure in the specimens during flexural testing, an edge chamfer was prepared with $\# 1000$ wet silicon carbide paper using a polishing machine. The specimens were immersed in $37^{\circ} \mathrm{C}$ deionized water for $50 \pm 2 \mathrm{~h}$ prior to the three-point bending test. A threepoint bending test, with a support span of $50 \mathrm{~mm}$, a cross-head speed of $5 \mathrm{~mm} / \mathrm{min}$, and $500 \mathrm{~N}$ load cell, was conducted at RT using a universal testing machine (EXS500N, Shimadzu, Kyoto, Japan). The FS and FM were calculated using Trapezium II software (Shimadzu). FS $(\sigma)$ and FM $(E)$ were calculated using the following equations:

$$
\begin{aligned}
& \sigma=3 F L / 2 b h^{2} \\
& E=F L^{3} / 4 b h^{3} d
\end{aligned}
$$

where, $F$ is the maximum load during the flexural test $(\mathrm{N}), L$ is the span distance $(50.0 \mathrm{~mm}), b$ is the specimen width, $h$ is the specimen height, and $d$ is the deflection $(\mathrm{mm})$

\section{Fracture toughness (FT) of NPs reinforced PMMA denture base}

The specimens were prepared as described in the effect of the MPS amount section above.

\section{FT test}

FT was determined using a three-point bending test according to ISO 20795-1:2013 ${ }^{19}$. The bar-shaped specimens, $8 \mathrm{~mm}$-height, $39 \mathrm{~mm}$-long, $4 \mathrm{~mm}$-width, were fabricated following a conventional compressive process and polished with \# 500, \#1000, \#1200 wet silicon carbide paper using a polishing machine (Nano2000, PACE Technologies) to achieve the required dimensions of $8.0 \pm 0.2 \times 39.0 \times 4.0 \pm 0.2 \mathrm{~mm}$. Pre-crack was created to the depth of $3.0 \pm 0.2 \mathrm{~mm}$ using low speed cutting machine (IsoMet 1000, Buehler, Lake Bluff, IL, USA). The razor blade (Feather-Cut, FEATHER Safety Razor, Gifu, Japan) was set of the bottom of the pre-crack and the crack length was cut with hand in a back and forth sliding motion to depth $0.1-0.4 \mathrm{~mm}$. The specimens were immersed in $37^{\circ} \mathrm{C}$ deionized water for 7 days $\pm 2 \mathrm{~h}$ prior to the three-point bending test. This test was conducted with a support span of $32 \mathrm{~mm}$, a cross-head speed of $1 \mathrm{~mm} / \mathrm{min}$, and $500 \mathrm{~N}$ load cells at RT, using a universal testing machine. The test was considered finished when the load dropped $1.0 \pm 0.2 \mathrm{~N}$ from the maximum load. The maximum load was recorded in N. An optical microscope with a micrometer scale was used to measure the length of the crack. FT $\left(K_{\max }\right)$ was calculated from the following equation:

$$
K_{\max }=f P_{\max } l_{t} \sqrt{10^{-3}} /\left(b_{t} h_{t}^{3 / 2}\right)
$$

where, $f$ is a geometrical function dependent on $x$ :

$$
\begin{gathered}
f(x)=3 x^{1 / 2}\left[1.99-x(1-x)\left(2.15-3.93 x+2.7 x^{2}\right)\right] / \\
{\left[2(1+2 x)(1-x)^{3 / 2}\right]}
\end{gathered}
$$

where, $x=a / h_{t}, P_{\max }$ is the maximum specimen load (N), $l_{t}$ is the span distance ( $32 \mathrm{~mm}), b_{t}$ is the specimen width, $h_{t}$ is the specimen height, and $a$ is the total crack length.

\section{Scanning electron microscopy (SEM)}

The fractured surfaces of the pure PMMA, 0, 0.061, $0.123,0.493,0.987$, and $1.974 \mathrm{~g}_{\mathrm{MPS}} / \mathrm{g}_{\text {silica }}$ of $1 \%$ silanized NP specimens after the three-point bending FT test were observed using a field emission scanning electron microscope (JEOL JSM7800F, JEOL). After the FT test, the fractured surfaces of specimens were carbon coated. The primary electron beam energy was operated at $5 \mathrm{kV}$ for each specimen. Backscattered electrons were used to create backscatter diffraction images.

\section{Color measurement}

A spectrophotometer (Ultrascan XE, Hunter Lab, Reston, VA, USA) was used to measure the color changes using the CIE $L^{*} a^{*} b^{*}$ color system. This system is based on three parameters for defining color: $L^{*}, a^{*}$, and $b^{*} . L^{*}$ represents lightness, $a^{*}$ represents red-green, and $b^{*}$ represents yellow-blue. The $\Delta E$ was calculated based on the $L^{*}, a^{*}$, and $b^{*}$ values obtained on a black background between the control and experimental group using the following equation:

$$
\left.\Delta E=\left[\left(L^{*}{ }_{1}-L^{*}{ }_{2}\right)^{2}+\left(a^{*}{ }_{1}-a^{*}\right)_{2}\right)^{2}+\left(b^{*}{ }_{1}-b^{*}\right)_{2}\right)^{1 / 2}
$$

where, the subscripts 1 and 2 refer to the color coordinates of the control and experimental groups, respectively. A high $\Delta E$ value indicates a large color difference. Three measurements were made on each specimen, and the average value was recorded.

\section{Statistical analysis}

The FS, FM, and $\Delta E$ of $0.246 \mathrm{~g}_{\mathrm{MPS}} / \mathrm{g}_{\text {silica }}$ of $0-15 \%$ amount of silanized NP groups and the FS, FM, FT and $\Delta E$ of the $0-1.974 \mathrm{~g}_{\mathrm{MPS}} / \mathrm{g}_{\text {silica }}$ of $1 \%$ amount of silanized NP groups were analyzed using One-way ANOVA and Tukey's post-hoc comparison (SPSS version.20, IBM, Armonk, NY, USA). The significance level was set at $\alpha=0.05$.

\section{RESULTS}

The TEM images revealed NPs of similar size that were evenly distributed in ETH with low aggregation and agglomeration (Fig. 1). The DLS analysis demonstrated 36-nm particles with homogeneous distribution (Fig. 2). The specific surface area determined by the automatic 
physisorption analyzer of the experimental NPs was 576 $\mathrm{m}^{2} / \mathrm{g}$.

The FTIR spectra of the dried samples demonstrated absorption peaks at 3,434, 2,986, 1,702, 1,631, 1,091, and $462 \mathrm{~cm}^{-1}$ representing hydrogen bonds, hydrocarbon chains, carbonyl groups, vinyl group, Si-O-Si (symmetrical stretch), and Si-O-Si (rocking), respectively (Fig. 3A ${ }^{10,20)}$. In contrast, hydrocarbon chains, carbonyl groups, and vinyl groups were not detected on the untreated NPs. The intensity of the absorption peak at $2,986,1,702$, and $1,631 \mathrm{~cm}^{-1}$ of the dried samples concentration dependently increased in the 0.061-1.974 $\mathrm{g}_{\text {MPS }} / \mathrm{g}_{\text {silica }}$ groups. The absorption peaks of centrifuged sample were the same as dried sample with intensity of absorption peaks at 2,986,1,702, and $1,631 \mathrm{~cm}^{-1}$ and reached the plateau at $0.246 \mathrm{~g}_{\mathrm{MPS}} / \mathrm{g}_{\text {silica }}$ group (Fig. 3B).

The amount of MPS adsorbed on the NP surface based on elemental carbon analysis in the dried groups ranged from $0.43-8.39 \mu \mathrm{mol} / \mathrm{m}^{2}$, while those of the centrifuged groups ranged from $0.49-3.11 \mu \mathrm{mol} / \mathrm{m}^{2}$ (Fig. 4). The number of MPS molecules chemisorbed on the NP surface ranged from $0.26-5.05$ molecule $/ \mathrm{nm}^{2}$ in the dried groups and $0.30-1.87$ molecule/ $\mathrm{nm}^{2}$ in the centrifuged groups (Fig. 4).

The FS of the $0.246 \mathrm{~g}_{\mathrm{MPS}} / \mathrm{g}_{\text {silica }}$ of $0-15 \%$ amount of silanized NP groups ranged from 84.3-105.8 $\mathrm{MPa}$ (Table 2). The FM of these groups ranged from 2.4-3.1 GPa (Table 2). One-way ANOVA of the FS and FM revealed significant differences between the groups. The Tukey-HSD test indicated that the FS and FM of the $0.246 \mathrm{~g}_{\mathrm{MPS}} / \mathrm{g}_{\text {silica }}$ of $1 \%$ amount of silanized NP group was significantly higher than those of the other groups. The FS of the $0-1.974 \mathrm{~g}_{\mathrm{MPS}} / \mathrm{g}_{\text {silica }}$ of $1 \%$ amount of silanized NP groups ranged from 80.3-105.8 MPa (Table 3). The FM of these groups ranged from 2.4-3.0 GPa (Table 3).

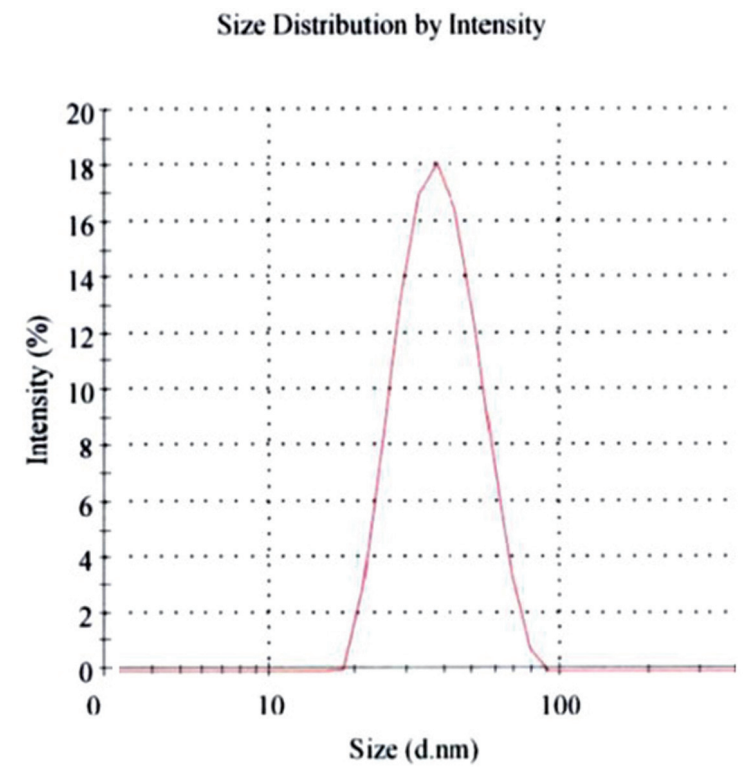

Fig. 2 NPs size and distribution of NPs determined by DLS (average size of experimental NPs is $36 \mathrm{~nm}$ ).
One-way ANOVA of the FS and FM of the 0-1.974 $\mathrm{g}_{\text {MPS }}$ / $\mathrm{g}_{\text {silica }}$ of $1 \%$ amount of silanized NP groups demonstrated significant differences between groups. The Tukey-HSD test showed that the FS and FM of the $0.246 \mathrm{~g}_{\text {MPS }} / \mathrm{g}_{\text {silica }}$ of $1 \%$ amount silanized NP group was significantly higher than those of the other groups.

The FT of the $0-1.974 \mathrm{~g}_{\mathrm{MPS}} / \mathrm{g}_{\text {silica }}$ of $1 \%$ amount of silanized NP groups ranged from $1.6-2.4 \mathrm{MPa} \cdot \mathrm{m}^{1 / 2}$ (Table 3). One-way ANOVA found significant differences between groups and the Tukey-HSD indicated that the

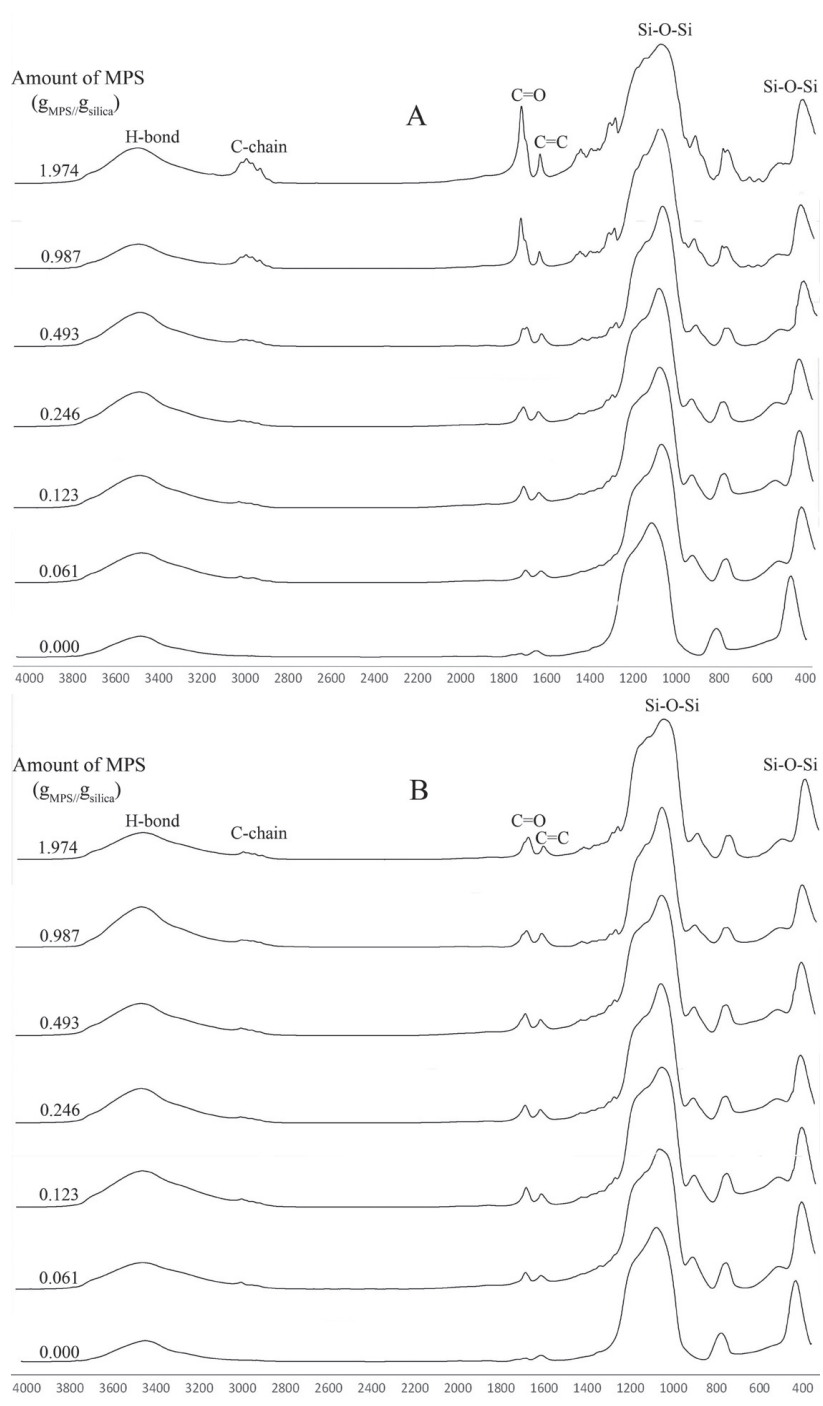

Fig. 3 FTIR spectra of A: dried samples showing absorption peaks at $3,434,2,986,1,702,1,631$, 1,091 , and $462 \mathrm{~cm}^{-1}$ representing hydrogen bonds, hydrocarbon chains, carbonyl groups, vinyl group, Si-O-Si (symmetrical stretch), and Si-O-Si (rocking), respectively.

B: The FTIR spectra of centrifuged samples shows that the absorption peaks at 3,434, 2,986, 1,702, $1,631,1,091$, and $462 \mathrm{~cm}^{-1}$ reached plateau in the $0.246 \mathrm{~g}_{\mathrm{MPS}} / \mathrm{g}_{\text {silica }}$ group. 


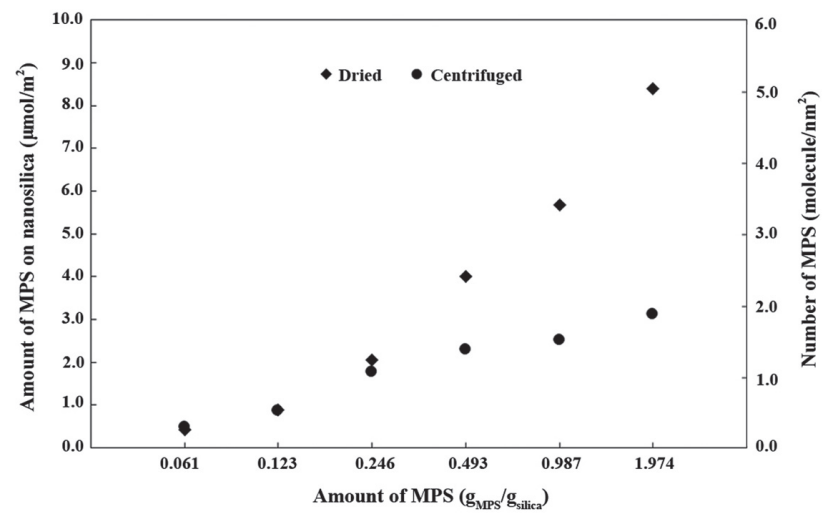

Fig. 4 Amount of MPS on the NP surface and number of molecules of MPS on the NP surface as determined by elemental analysis in the dried groups and centrifuged groups.
FT of the $0.246 \mathrm{~g}_{\mathrm{MPS}} / \mathrm{g}_{\text {silica }}$ of $1 \%$ amount of silanized NP group was significantly higher than those of the other groups.

The $\Delta E$ of the $0.246 \mathrm{~g}_{\mathrm{MPS}} / \mathrm{g}_{\text {silica }}$ of $0.25-15 \%$ amount of silanized NP groups ranged from 0.7-1.8 (Table 2). One-way ANOVA revealed significant differences in $\Delta E$ between groups and the Tukey-HSD indicated that the $\Delta E$ of the $0.246 \mathrm{~g}_{\mathrm{MPS}} / \mathrm{g}_{\text {silica }}$ of $15 \%$ amount of silanized $\mathrm{NP}$ group was significantly higher than those of the other groups. The $\Delta E$ of the $0-1.974 \mathrm{~g}_{\mathrm{MPS}} / \mathrm{g}_{\text {silica }}$ of $1 \%$ amount of silanized NP groups ranged from $0.6-0.8$ (Table 3 ). Oneway ANOVA revealed no significant differences between groups.

\section{DISCUSSION}

This study was to investigate the chemisorbed amounts of silanized on NPs and to investigate the effect of

Table 2 Flexural strength, flexural modulus, and $\Delta E$ of $0.246 \mathrm{~g}_{\mathrm{MPs}} / \mathrm{g}_{\text {silica }}$ with different amount of NP groups

\begin{tabular}{lccc}
\hline \multirow{2}{*}{ Conditions } & Flexural strength & Flexural modulus & \multirow{2}{*}{$\Delta E$} \\
\cline { 2 - 3 } control (no filler) & $(\mathrm{MPa})$ & $(\mathrm{GPa})$ & - \\
$0.25 \% \mathrm{NP}$ & $85.2(3.8)^{\mathrm{a}}$ & $2.4(0.1)^{\mathrm{a}}$ & $0.8(0.2)^{\mathrm{a}}$ \\
$0.5 \% \mathrm{NP}$ & $93.4(4.2)^{\mathrm{b}}$ & $2.7(0.1)^{\mathrm{b}}$ & $0.7(0.1)^{\mathrm{a}}$ \\
$1 \% \mathrm{NP}$ & $94.5(3.1)^{\mathrm{b}}$ & $2.7(0.0)^{\mathrm{b}}$ & $0.8(0.1)^{\mathrm{a}}$ \\
$5 \% \mathrm{NP}$ & $105.8(3.4)^{\mathrm{c}}$ & $3.0(0.0)^{\mathrm{c}}$ & $1.4(0.1)^{\mathrm{b}}$ \\
$10 \% \mathrm{NP}$ & $97.0(2.5)^{\mathrm{b}}$ & $2.9(0.1)^{\mathrm{c}}$ & $1.6(0.1)^{\mathrm{b}, \mathrm{c}}$ \\
$15 \% \mathrm{NP}$ & $89.3(3.6)^{\mathrm{a}, \mathrm{b}}$ & $3.1(0.1)^{\mathrm{c}}$ & $1.8(0.2)^{\mathrm{c}}$ \\
\hline
\end{tabular}

$\%(\mathrm{w} / \mathrm{w})$

Mean values $(n=8)$ and standard deviations in parentheses.

For each property, values denoted with same letters are not significantly different $(p>0.05)$.

Table 3 Flexural strength, flexural modulus, fracture toughness, and $\Delta \mathrm{E}$ of $1 \%$ amount of NP with different amount of MPS groups

\begin{tabular}{|c|c|c|c|c|}
\hline \multirow{2}{*}{ Conditions } & Flexural strength & Flexural modulus & Fracture toughness & \multirow{2}{*}{$\Delta E$} \\
\hline & $(\mathrm{MPa})$ & $(\mathrm{GPa})$ & $\left(\mathrm{MPa} \cdot \mathrm{m}^{1 / 2}\right)$ & \\
\hline control (no filler) & $85.2(3.8)^{\mathrm{a}}$ & $2.4(0.1)^{\mathrm{a}}$ & $1.9(0.2)^{\mathrm{a}, \mathrm{b}}$ & - \\
\hline 0.000 (unsilanized) & $81.0(5.0)^{\mathrm{a}}$ & $2.6(0.1)^{\mathrm{a}}$ & $1.6(0.4)^{\mathrm{a}}$ & $0.6(0.1)^{\mathrm{a}}$ \\
\hline 0.061 & $80.3(5.4)^{\mathrm{a}}$ & $2.4(0.0)^{\mathrm{a}}$ & $1.9(0.3)^{\mathrm{a}, \mathrm{b}}$ & $0.7(0.1)^{\mathrm{a}}$ \\
\hline 0.123 & $97.1(1.6)^{\mathrm{b}}$ & $2.7(0.1)^{\mathrm{b}}$ & $2.0(0.3)^{\mathrm{b}}$ & $0.6(0.1)^{\mathrm{a}}$ \\
\hline 0.246 & $105.8(3.4)^{\mathrm{c}}$ & $3.0(0.0)^{\mathrm{c}}$ & $2.4(0.3)^{\mathrm{c}}$ & $0.8(0.1)^{\mathrm{a}}$ \\
\hline 0.493 & $98.2(3.3)^{\mathrm{b}}$ & $2.6(0.0)^{\mathrm{b}}$ & $2.0(0.3)^{\mathrm{b}}$ & $0.8(0.2)^{\mathrm{a}}$ \\
\hline 0.987 & $93.9(3.6)^{\mathrm{b}}$ & $2.6(0.0)^{\mathrm{b}}$ & $1.9(0.2)^{\mathrm{a}, \mathrm{b}}$ & $0.7(0.1)^{\mathrm{a}}$ \\
\hline 1.974 & $84.6(4.0)^{\mathrm{a}}$ & $2.3(0.1)^{\mathrm{a}}$ & $1.6(0.2)^{\mathrm{a}}$ & $0.6(0.1)^{\mathrm{a}}$ \\
\hline
\end{tabular}

Amount of MPS ( $\left.\mathrm{g}_{\mathrm{mps}} / \mathrm{g}_{\text {silica }}\right)$

Mean values $(n=8)$ and standard deviations in parentheses.

For each property, values denoted with same letters are not significantly different $(p>0.05)$. 
various amounts of NPs and various amounts of MPS silanized on the NPs on mechanical properties of NPs reinforced PMMA denture base.

FTIR results indicated that the silanization process used in this study was effective. The FTIR spectra in the dried NP groups as a function of MPS amount demonstrated 2,986, 1,702, and $1,631 \mathrm{~cm}^{-1}$ peak intensities corresponding to the chemisorbed and physisorbed MPS, which gradually increased from the 0.061 to $1.974 \mathrm{~g}_{\mathrm{MPS}} / \mathrm{g}_{\text {silica }}$ groups. In the centrifuged groups, the adsorption peak intensity reached the plateau at the $0.246 \mathrm{~g}_{\text {MPS }} / \mathrm{g}_{\text {silica }}$ groups. The spectra of the $>0.246 \mathrm{~g}_{\text {MPS }} / \mathrm{g}_{\text {silica }}$ centrifuged groups indicated the complete removal of physisorbed MPS by isopropanol and centrifugation at 20,000 rpm.

The elemental analysis results indicated that the amount of MPS required to form a chemisorbed monolayer on the NP surface was $1.77 \mu \mathrm{mol} / \mathrm{m}^{2}$ corresponded to approximately 1.07 MPS molecules on $1 \mathrm{~nm}^{2}$ of the NP surface. The plateauing of the amount of MPS in the chemisorbed monolayer layer probably occurred because of the steric hindrance of the organic groups of the MPS molecule ${ }^{18)}$. Silica has 3 or $4 \mathrm{Si}-\mathrm{OH}$ groups per $\mathrm{nm}^{2}$ of the NP surface ${ }^{21)}$; therefore, unreacted $\mathrm{Si}-\mathrm{OH}$ groups on the NP still remained. The amount of chemisorbed MPS in this study was 7 times lower than that theoretically calculated by Arkles $\left(12.82 \mu \mathrm{mol} / \mathrm{m}^{2}\right)^{11)}$. In contrast to the study of Arksornnukit et al. ${ }^{22)}$, they reported that $12.88 \mu \mathrm{mol} / \mathrm{m}^{2}$ was required for monolayer coverage and 7.7 MPS molecules per $\mathrm{nm}^{2}$ of silica based on Arkles's equation. This difference is probably due to the difference in the in size of the silica particles between the two studies. Larger silica particles provide adequate space for silane oligomer adsorption. Therefore, higher molecular weight molecules would also be chemisorbed on the silica surface.

The orientation of the MPS molecule on the NPs can be parallel or perpendicular. The parallel orientation results in one MPS molecule reacting with two $\mathrm{Si}-\mathrm{OH}$ molecules on the NP surface, generating a hydrogen bond between $\mathrm{C}=\mathrm{O}$ of MPS and $\mathrm{Si}-\mathrm{OH}$ on the NP surface and a siloxane bond between $\mathrm{Si}-\mathrm{OH}$ of MPS and $\mathrm{Si}$ $\mathrm{OH}$ on the NP surface. The perpendicular orientation results in one MPS molecule reacting with one $\mathrm{Si}-\mathrm{OH}$ molecule, generating a siloxane bond between $\mathrm{Si}-\mathrm{OH}$ of MPS and Si-OH on the NP surface ${ }^{18)}$. The behavior of the $\mathrm{C}=\mathrm{O}$ band in MPS molecule indicates that the orientation behavior of MPS depends upon the number of chemisorbed MPS molecules on $1 \mathrm{~nm}^{2} \mathrm{NP}$ surface. The result of this study also showed that the parallel orientation of MPS adsorption was between 0.61-1.07 molecule on $1 \mathrm{~nm}^{2}$ which showed $\mathrm{C}=\mathrm{O}$ band at 1,702 $\mathrm{cm}^{-1}$ representing hydrogen bond $\mathrm{C}=\mathrm{O}$ group with $\mathrm{Si}-\mathrm{OH}$ groups. While, the groups which exceeded 1.07 molecule on $1 \mathrm{~nm}^{2}$, a new $\mathrm{C}=\mathrm{O}$ band at $1,720 \mathrm{~cm}^{-1}$ appeared due to the free $\mathrm{C}=\mathrm{O}$ (Fig. 5) ${ }^{10,13)}$. This results indicated that MPS molecules oriented perpendicular to the NP surface. MPS molecules can be further forced chemisorption to the NP beyond the plateau phase which was demonstated in Fig. 4. Excess amount of MPS will likely transform

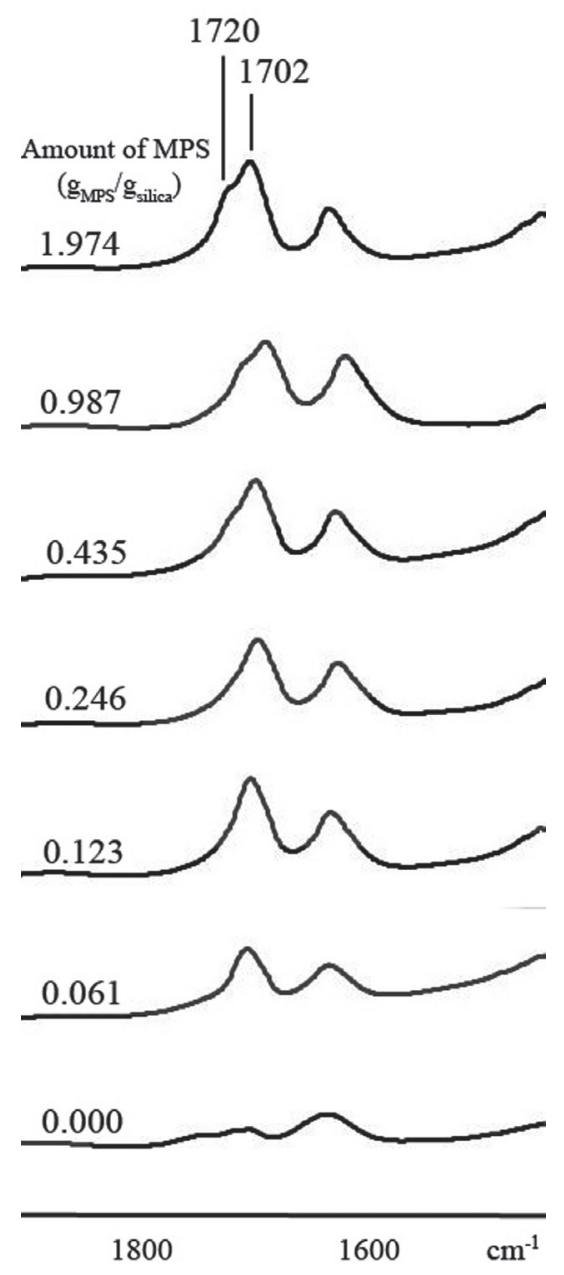

Fig. 5 The 1,800-1,600 $\mathrm{cm}^{-1}$ interval showing the location of the $\mathrm{C}=\mathrm{O}$ peak at $1,702 \mathrm{~cm}^{-1}$.

This peak reached plateau at $0.246 \mathrm{~g}_{\mathrm{MPS}} / \mathrm{g}_{\text {silica }}$. Above this MPS amount, a peak at $1,720 \mathrm{~cm}^{-1}$ is observed. The height of this peaked increases as the MPS amount increases.

the direction of adsorbed MPS molecules at NP surface from parallel to perpendicular. As a result, the amount of MPS per surface area of NP increased from 1.07 to 1.87 molecule/ $\mathrm{nm}^{2}$.

The FS and FM results showed differences based on the amount of silanized NPs incorporated into the PMMA. Therefore, the null hypothesis that there would be no differences in the FS and FM of PMMA denture base reinforced with different amounts of silanized NPs was rejected. The FS and FM of the PMMA containing $0.246 \mathrm{~g}_{\mathrm{MPS}} / \mathrm{g}_{\text {silica }}$ silanized NP steadily increased in the $0.25-1 \%$ groups. The increasing amounts of silanized NP resulted in more covalent linkages at the interface between the NPs and the PMMA matrix. However, when the NP amount exceeded 1\%, the interparticle spacing decreased, allowing for increased agglomeration of silanized NPs (Fig. 6). This agglomeration generated stress concentration at the agglomerated particles and 


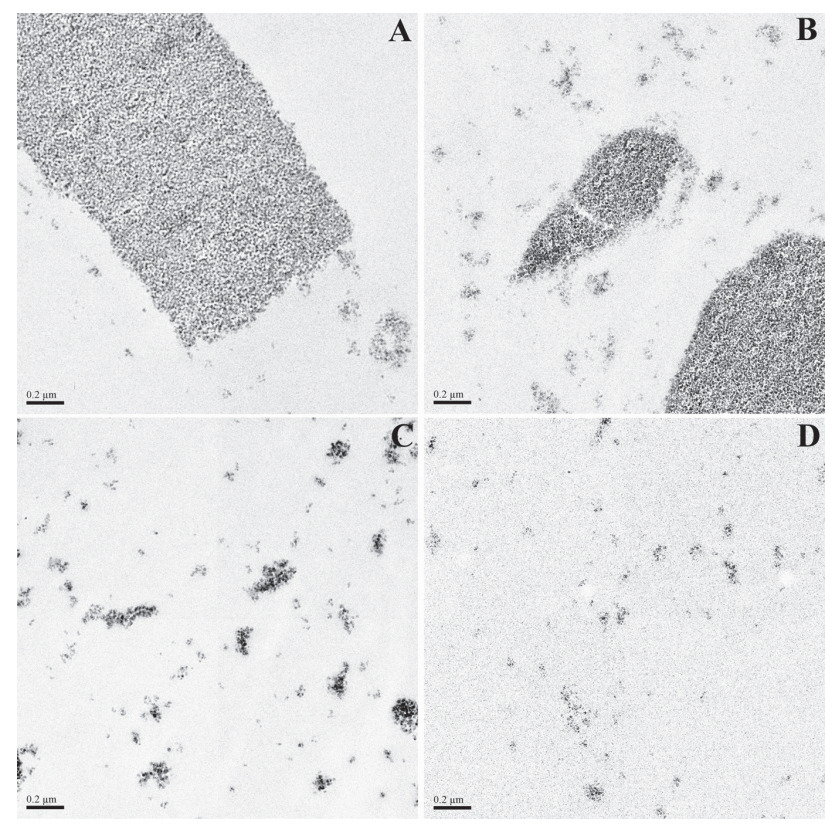

Fig. 6 Representative TEM images (9.6k magnification) of PMMA containing $0.246 \mathrm{~g}_{\mathrm{MPS}} / \mathrm{g}_{\text {silica }}$ silanized NP. A: The highly agglomerated of NP of $15 \%$, B: $10 \%$ (w/w) PMMA, C: The slightly agglomerated of NP of $5 \%(w / w)$ of PMMA, D: The homogeneous dispersion of silanized NP 1\% (w/w) of PMMA.

decreased the mechanical properties of the PMMA matrix $^{23-25)}$. Thus, the FS in the groups containing $>1 \%$ silanized NPs was reduced, however, there was no significant differences in FM between these groups. The results of the present study indicated that the optimum loading amounts of $36-\mathrm{nm}$ NPs was $1 \%$, which generated a homogeneous dispersion of the silanized NPs in the PMMA matrix, resulting in the highest FS and FM (Fig. 6).

The FS, FM, and FT results were different based on the amount of MPS on the NPs. Therefore, the null hypotheses that there would be no differences in the FS, FM, or FT of PMMA denture base reinforced with NPs with various amounts of silanization were rejected. PMMA containing $0.246 \mathrm{~g}$ MPS $/ \mathrm{g}_{\text {silica }}$ silanized NPs showed the highest FS, FM, and FT. The results from elemental analysis showed that a chemisorbed monolayer was presented in the $0.246 \mathrm{~g}_{\mathrm{MPS}} / \mathrm{g}_{\text {silica }}$ group. The chemisorbed monolayer of MPS creates covalent linkages between the nanoparticles and the polymer matrix ${ }^{2,9,10)}$. The covalent bond between the NPs and PMMA via MPS molecule provide adequate stress transfer from the matrix to the $\mathrm{NPs}^{17,26)}$. In PMMA containing unsilanized NPs, the bonding at the interface between the inorganic silica and the organic polymer matrix is poor ${ }^{2)}$. When a force is placed, stress will be concentrated at the interface between the filler and the matrix. The stress cannot be effectively transferred; therefore, it will cause cracks, and finally induces material failure, which explains the lowest FS, FM, and FT values observed in the PMMA containing unsilanized NPs groups. However, the amount of MPS is also an important factor. The FS, FM, and FT of the 0.061 and $0.123 \mathrm{~g}_{\mathrm{MPS}} / \mathrm{g}_{\text {silica }}$ groups were lower than that of the $0.246 \mathrm{~g}_{\mathrm{MPS}} / \mathrm{g}_{\text {silica }}$ group. This can be attributed to incomplete NP surface coverage by the MPS molecules. The remaining $\mathrm{Si}-\mathrm{OH}$ on the silica surface cannot react with PMMA, creating a weak interface between the PMMA and silica surface. Moreover, the $0.493,0.987$, and $1.974 \mathrm{~g}_{\mathrm{MPS}} / \mathrm{g}_{\text {silica }}$ groups, which have a physisorbed layer on the NP surface as demonstated by the elemental analysis, also showed lower FS, FM, and FT values compared with the $0.246 \mathrm{~g}_{\mathrm{MPS}} / \mathrm{g}_{\text {silica }}$ group. This resulted from the physisorbed layer, which contains weak Van der Waal's forces and hydrogen bonds.

The SEM images can explain the cause, location of failure, and the mechanism of particle reinforcement of composites (Fig. 7). The fractured surface for the pure PMMA matrix revealed a brittle behavior characterized by a large smooth area. Higher magnification showed that the cracks propagated as river lines (Fig. 7A) ${ }^{27}$. This indicates a weak resistance to crack propagation, and minimal energy was required to fracture the specimen. The 1\% unsilanized NP reinforced PMMA denture base showed a smooth fractured surface with agglomeration and uncovered NP, indicating that there were no chemical bonds between the inorganic silica and the organic resin matrix (Fig. 7B ${ }^{23)}$. The fractured surface of the 0.061 and $0.123 \mathrm{~g}_{\mathrm{MPS}} / \mathrm{g}_{\text {silica }}$ MPS groups showed rougher fractured surfaces and fractured surface cavitation. This indicated that the material was tough (Fig. 7C and D). The PMMA containing $0.246 \mathrm{~g}_{\mathrm{MPS}} /$ $\mathrm{g}_{\text {silica }}$ of $1 \%$ amounts of NPs revealed a tougher behavior characterized by the roughest fractured surface, out of the plane cracking, fractured surface cavitation, and NP debonding/pullout (Fig. 7E). This behavior requires additional energy to fracture the materials, resulting in increased FS and FT. However, the PMMA containing $0.493,0.987$, and $1.974 \mathrm{~g}_{\mathrm{MPS}} / \mathrm{g}_{\text {silica }}$ of $1 \%$ amount of NP groups revealed ductile behavior characterized by large fracture surface cavitation. The over adsorbed amount of MPS of these groups created a physisorbed layer on nanosilica surface resulted in crack propagation along physisorbed layer (Fig. 7F-H). The chemisorbed MPS monolayer/nanoparticle interface is an important factor in the toughening mechanism of nanocomposite materials. Cracks encounter particles as obstacles, which deviate and branch the crack front. In addition, a large amount of energy is consumed at the particle/ matrix interface under strong bonding conditions ${ }^{16,28)}$.

This study synthesized monodispersed NP and silanized with MPS in monodisperse suspension that allowed chemisorbed monolayer formation. One percent (w/w) of NP incorporated into PMMA increased FS, FM and FT of PMMA denture base. This higher fracture resistance would be beneficial in terms of preventing fracture at the thin denture base area such as midline in complete denture and area around attachment housing in implant retained overdenture. The lesser amount of nano-sized silica created reinforcement of PMMA in this study helped in reducing cost of material, compared to 

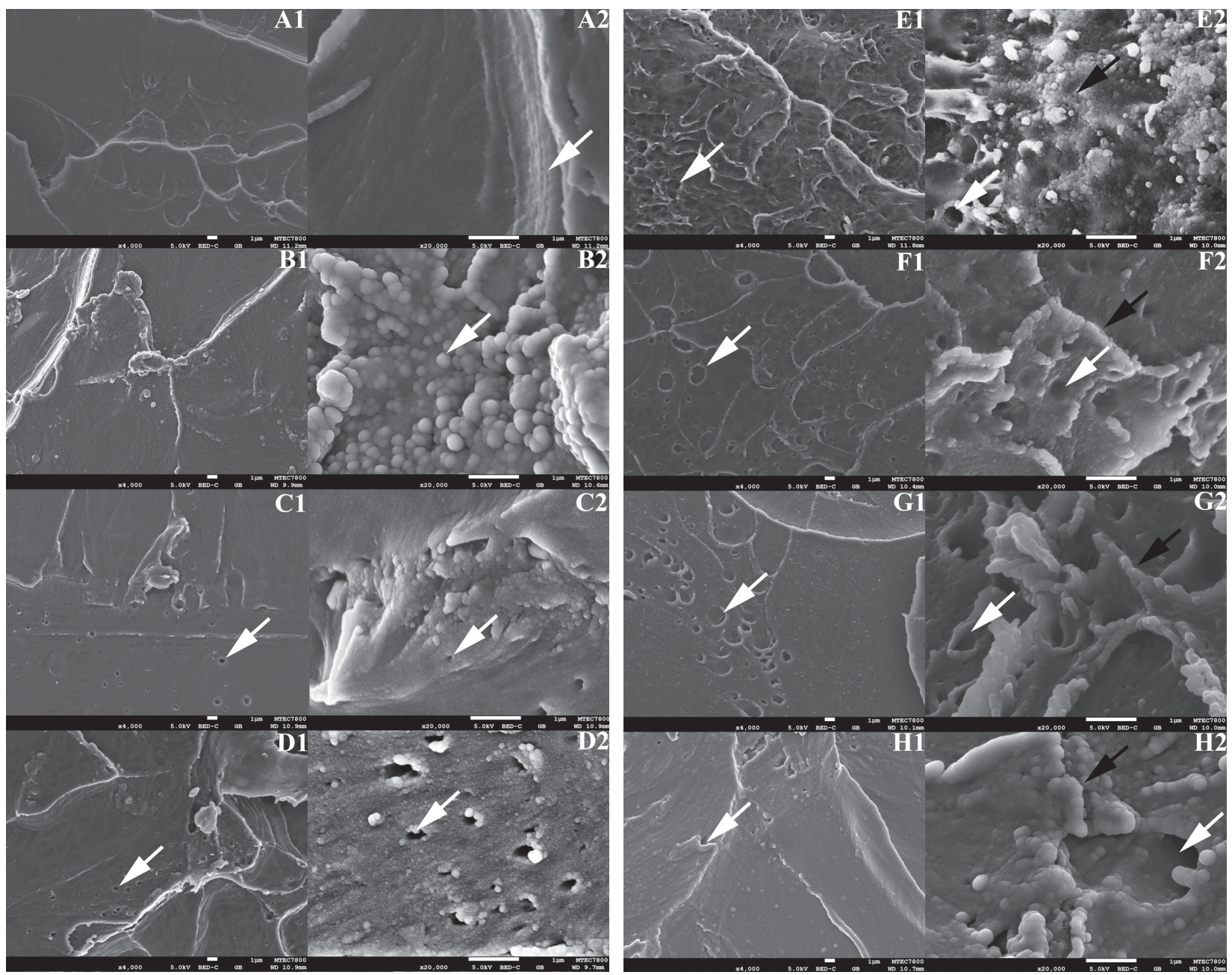

Fig. 7 Representative SEM images the fractured FT specimen surfaces.

A: Pure PMMA, A1: The smooth fractured surface, A2: White arrow showed the river lines, B: 1\% (w/w) unsilanized NP, B1: The smooth fractured surface, B2: White arrow showed agglomeration and uncoverage of NP, C: 1\% (w/w) 0.061 MPS amount, D: 1\% (w/w) 0.123 MPS amount, C1, C2, D1, D2: The rougher fractured surface. White arrows showed cavitation on fractured surface. E: 1\% (w/w) 0.246 MPS amount, E1: The roughest fractured surface, E2: Black arrow showed the NP pullout and white arrow showed cavitation on fractured surface, F: 1\% (w/w) 0.493 MPS amount, G: 1\% (w/w) 0.987 MPS amount, H: 1\% (w/w) 1.974 MPS amount, F-H: White arrows showed large cavitation and black arrows showed crack propagation along physisorbed layer of silanized NP. 1: 4k magnification, 2: 20k magnification.

the previous study which advocated $5 \%(\mathrm{w} / \mathrm{w})^{2}$. This difference is probably due to the difference in level of dispersion. The reinforcement mechanism resulted from molecular interaction between particle and matrix. In contrast to the monodisperse NP in the present study, the agglomeration of particles in the higher amount of nano-sized filler, resulted in the reduction of surface area to volume ratio. Therefore, it required more amounts of particles to improve mechanical properties ${ }^{29)}$.

$\Delta E$ between the groups were measured using the perceptibility threshold (PT) and acceptability threshold (AT). Several studies used $\Delta E=1.0$ as the threshold at which $50 \%$ of observers can distinguish a $\Delta E$ between 2 objects (PT) and $\Delta E=3.7$ as the threshold at which $50 \%$ of observers accepted a $\Delta E$ (AT) ${ }^{30-32)}$. The $\Delta E$ of this study indicated that the increasing amounts of silanized NP and amount of MPS silanized on NPs in PMMA denture base affected the color of the material; however, the difference from pure PMMA was within the AT. This is likely due to the refractive index of NP (1.45) which is very close to those of MPS and PMMA denture base ${ }^{33)}$.

\section{CONCLUSIONS}

Within the limitations of this study, it was concluded that the amount of MPS in a chemisorbed monolayer on the 36-nm spherical NPs was $1.77 \mu \mathrm{mol} / \mathrm{m}^{2}$ and the number of MPS molecules in the chemisorbed monolayer was 
1.07 molecule $/ \mathrm{nm}^{2}$. Arkles's equation is not applicable in calculating the chemisorbed amount of silane on NPs. The PMMA denture base reinforced with $0.246 \mathrm{~g}_{\mathrm{MPS}} / \mathrm{g}_{\text {silica }}$ of $1 \%$ amount of silanized NPs provided the highest FS, $\mathrm{FM}$, and FT with a clinically acceptable $\Delta E$.

\section{ACKNOWLEDGMENTS}

We thank Dr. Kevin TOMPKINS for his critical review and editing of this manuscript.

\section{REFERENCES}

1) Ashton H. The incorporation of nanomaterials into polymer media. Polymer Nanocomposites Handbook 2009: 4-10.

2) Du M, Zheng Y. Modification of silica nanoparticles and their application in UDMA dental polymeric composites. Polym Compos 2007; 28: 198-207.

3) Judeinstein P, Sanchez C. Hybrid organic-inorganic materials: A land of multidisciplinarity. J Mater Chem 1996; 6: 511-525.

4) Stöber W, Fink A, Bohn E. Controlled growth of monodisperse silica spheres in the micron size range. J Colloid Interface Sci 1968; 26: 62-69.

5) Bogush GH, Tracy MA, Zukoski IV CF. Preparation of monodisperse silica particles: Control of size and mass fraction. J Non-Cryst Solids 1988; 104: 95-106.

6) Chruściel J, Ślusarski L. Synthesis of nanosilica by the sol-gel method and its activity toward polymers. Mater Sci Eng C Mater Biol Appl 2003; 21: 461-469.

7) Chen SL, Dong P, Yang GH, Yang JJ. Kinetics of formation of monodisperse colloidal silica Particles through the hydrolysis and condensation of tetraethylorthosilicate. Ind Eng Chem Res 1996; 35: 4487-4493.

8) Jafarzadeh M, Rahman IA, Sipaut CS. Synthesis of silica nanoparticles by modified sol-gel process: the effect of mixing modes of the reactants and drying techniques. J Sol-Gel Sci Technol 2009; 50: 328-336.

9) Plueddemann EP. Silane coupling agents. 2 ed. New York: Plenum Press; 1991; 120-133.

10) Miller JD, Ishida H. Quantitative monomolecular coverage of inorganic particulates by methacryl-functional silanes. Surf Sci 1984; 148: 601-622.

11) Arkles B. Silane coupling agent chemistry. Pennsylvania: Petrarch Systems Catalogue; 1987: 59.

12) Posthumus W, Magusin PC, Brokken-Zijp JC, Tinnemans AH, Van der Linde R. Surface modification of oxidic nanoparticles using 3-methacryloxypropyltrimethoxysilane. J Colloid Interface Sci 2004; 269: 109-116.

13) Söderholm KJM, Shang SW. Molecular orientation of silane at the surface of colloidal silica. J Dent Res 1993; 72: 10501054.

14) Pires-de-Souza FdCP, Panzeri H, Vieira MA, Garcia LdFR, Consani S. Impact and fracture resistance of an experimental acrylic polymer with elastomer in different proportions. Mat Res 2009; 12: 415-418.

15) Vojdani M, Giti R. Polyamide as a denture base material: A literature review. J Dent 2015; 16: 1-9.
16) Alhareb AO, Akil HM, Ahmad ZA. Impact strength, fracture toughness and hardness improvement of PMMA denture base through addition of nitrile rubber/ceramic fillers. Saudi J Dent Res 2017; 8: 26-34.

17) Chaijareenont $\mathrm{P}$, Takahashi $\mathrm{H}$, Nishiyama N, Arksornnukit M. Effect of different amounts of 3-methacryloxypropyltrime thoxysilane on the flexural properties and wear resistance of alumina reinforced PMMA. Dent Mater J 2012; 31: 623-628.

18) Vrancken KC, Van Der Voort P, Possemiers K, Vansant EF. Surface and structural properties of silica gel in the modification with $\gamma$-aminopropyltriethoxysilane. J Colloid Interface Sci 1995; 174: 86-91.

19) ISO 20795-1: 2013. Dentistry - Base polymers - Part 1: Denture base polymers, 2nd ed, International Organization for Standardization, Geneva, 2013.

20) Nishiyama N, Shick R, Ishida H. Adsorption behavior of a silane coupling agent on colloidal silica studied by gel permeation chromatography. J Colloid Interface Sci 1991; 143: 146-156.

21) Young GJ. Interaction of water vapor with silica surfaces. J Colloid Interface Sci 1958; 13: 67-85

22) Arksornnukit M, Takahashi H, Nishiyama N. Effects of silane coupling agent amount on mechanical properties and hydrolytic durability of composite resin after hot water storage. Dent Mater J 2004; 23: 31-36.

23) Htang A, Ohsawa M, Matsumoto H. Fatigue resistance of composite restorations: Effect of filler content. Dent Mater 1995; 11: 7-13.

24) Islam MS, Masoodi R, Rostami H. The effect of nanoparticles percentage on mechanical behavior of silica-epoxy nanocomposites. J Nanosci 2013; 2013; 275037.

25) Rashahmadi S, Hasanzadeh R, Mosalman S. Improving the mechanical properties of poly methyl methacrylate nanocomposites for dentistry applications reinforced with different nanoparticles. Polym Plast Technol Eng 2017: 1-11.

26) Hong RY, Fu HP, Zhang YJ, Liu J, Wang H, Li Z, Zheng Y. Surface-modified silica nanoparticles for reinforcement of PMMA. J Appl Polym Sci 2007; 105: 2176-2184.

27) Becker WT, Lampman S. Fracture appearance and mechanisms of deformation and fracture. ASM International 2002: 35-41.

28) Zhang XY, Zhang XJ, Huang ZL, Zhu BS, Chen RR. Hybrid effects of zirconia nanoparticles with aluminum borate whiskers on mechanical properties of denture base resin PMMA. Dent Mater J 2014; 33: 141-146.

29) Rosso P, Ye L, Friedrich K, Sprenger S. A toughened epoxy resin by silica nanoparticle reinforcement. J Appl Polym Sci 2006; 100: 1849-1855.

30) Khashayar G, Bain PA, Salari S, Dozic A, Kleverlaan CJ, Feilzer AJ. Perceptibility and acceptability thresholds for colour differences in dentistry. J Dent 2014; 42: 637-644.

31) Johnston WM, Kao EC. Assessment of appearance match by visual observation and clinical colorimetry. J Dent Res 1989; 68: 819-822.

32) Kuehni RG, Marcus RT. An experiment in visual scaling of small color differences. Color Res Appl 1979; 4: 83-91.

33) Kim KJ, White J. Dispersion of agglomerated nanoparticles in rubber processing. polymer Nanocomposites Handbook: CRC Press; 2009: 127. 